
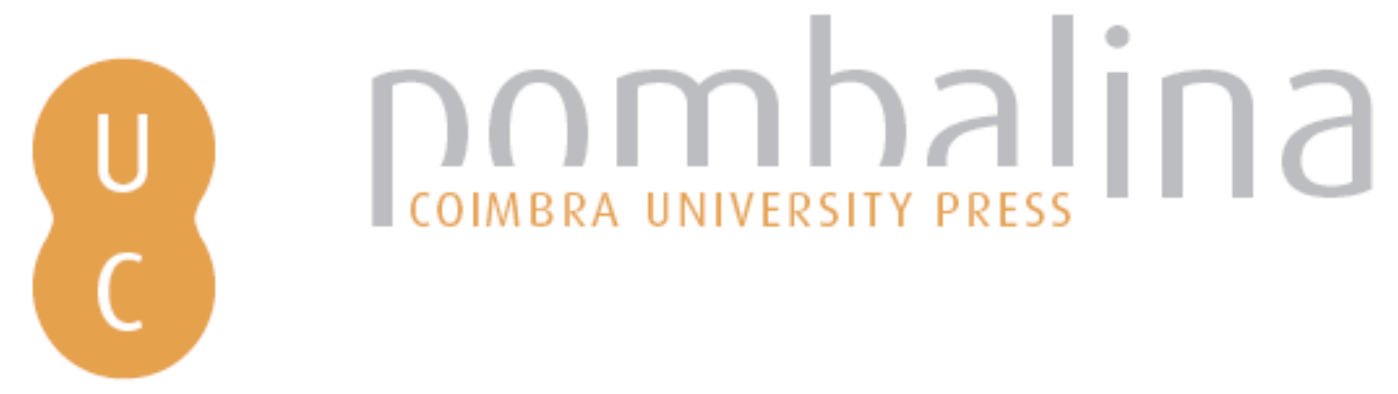

\title{
Aplicación de la bibliometría al estudio del fondo antiguo: estado de la cuestión y vías de investigación.
}

Autor(es): $\quad$ Pulgarín Guerrero, Antonio; Herrera Morillas, José Luis

Publicado por: Imprensa da Universidade de Coimbra

URL

persistente: URI:http://hdl.handle.net/10316.2/31925

DOI: $\quad$ DOI:http://dx.doi.org/10.14195/978-989-26-0869-3_21

Accessed : $\quad$ 26-Apr-2023 16:20:50

A navegação consulta e descarregamento dos títulos inseridos nas Bibliotecas Digitais UC Digitalis, UC Pombalina e UC Impactum, pressupõem a aceitação plena e sem reservas dos Termos e Condições de Uso destas Bibliotecas Digitais, disponíveis em https://digitalis.uc.pt/pt-pt/termos.

Conforme exposto nos referidos Termos e Condições de Uso, o descarregamento de títulos de acesso restrito requer uma licença válida de autorização devendo o utilizador aceder ao(s) documento(s) a partir de um endereço de IP da instituição detentora da supramencionada licença.

Ao utilizador é apenas permitido o descarregamento para uso pessoal, pelo que o emprego do(s) título(s) descarregado(s) para outro fim, designadamente comercial, carece de autorização do respetivo autor ou editor da obra.

Na medida em que todas as obras da UC Digitalis se encontram protegidas pelo Código do Direito de Autor e Direitos Conexos e demais legislação aplicável, toda a cópia, parcial ou total, deste documento, nos casos em que é legalmente admitida, deverá conter ou fazer-se acompanhar por este aviso.

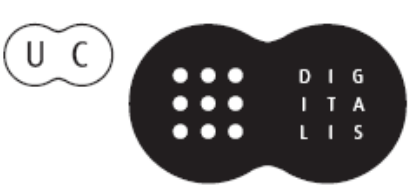


Maria Manuel Borges

Elias Sanz Casado

Coordenação

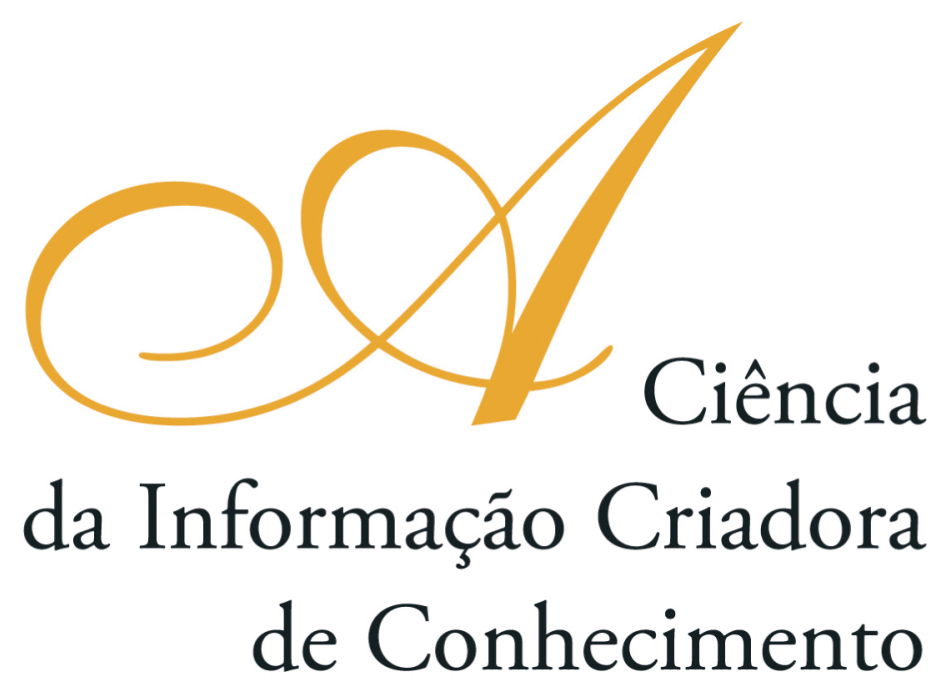

Vol. I I

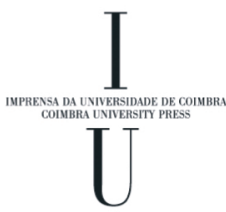

- COImbra 2009 


\title{
Título: Aplicación de la Bibliometría AL ESTUdio del FONDO ANTIGUO: ESTADO DE LA CUESTIÓN Y VÍAS DE INVESTIGACIÓN.
}

\author{
Antonio Pulgarín Guerrero \\ Universidad de Extremadura (Espanha) \\ José Luis Herrera Morillas \\ Universidad de Extremadura (Espanha)
}

\section{Resumen}

La aplicación de las técnicas y métodos de la Bibliometría al estudio de las colecciones de libros antiguos nos parece un tema de interés, que presenta un panorama de investigación a penas desarrollado. Partiendo de esta hipótesis, con este trabajo queremos comprobar, en primer lugar, si se han realizado estudios de estas características, y si es así, recopilarlos y analizarlos para establecer las cualidades o características que los definen. En segundo lugar, esbozar unas posibles vías de investigación que puedan orientar la aplicación de la Bibliometría al estudio de las colecciones de fondo antiguo conservadas en Espańa, haciendo hincapié en los aspectos diferenciadores de los impresos antiguos (papel destacado de los impresores, de los costeadores, variedad de idiomas en un mismo lugar de impresión, diferencias entre emisiones y estados dentro de una misma edición, la presencia de los preliminares, etc.). Estas vías la concretamos en torno a tres ejes o ámbitos: 1 . Colecciones de bibliotecas; 2. Bases de datos y catálogos colectivos especializados; 3 . Revistas científicas especializadas y afines. De cada una establecemos las cualidades que definen el objeto de estudio, estableciendo un listado de ejemplos a los que se podrían aplicar las investigaciones; y también, los indicadores bibliométricos más propios para utilizar en cada caso. A modo de ilustración, por ejemplo, en el caso del fondo de una biblioteca podrían ser útiles indicadores como: distribución de los fondos por ańos de edición, por autores, por impresores, distribución temática y distribución por idioma; mientras que en el caso de los artículos de una revista se aplicarían: la ley de Price para ver el crecimiento del número de artículos y autores, la ley de Lotka para la relación de proporcionalidad entre el número de artículos y autores, o el índice de productividad para la identificación de los principales productores, etc.; o si elegimos estudiar una base de datos podríamos analizar la información recuperada a través del campo impresores para definir los círculos más productivos en un periodo cronológico concreto.

\begin{abstract}
The application of the techniques and methods of bibliometrics to the study of rare book and manuscript collections seems to us to be a topic of interest as it presents a panorama of potential research that appears to barely have been touched. Given this hypothesis, in the present work our aim is twofold: firstly to check whether there indeed have been studies made along these lines, and, if so, to review and analyze them, establishing their defining qualities or characteristics; and secondly, to outline some possible lines of inquiry that could guide the application of bibliometrics to the study of rare book collections conserved in Spain. The focus is on the differentiating aspects of printed books (the roles of the printer and the bookseller,
\end{abstract}


variety of languages at a single print-shop, differences between issues and states within the same edition, the presence of the preliminary drafts, etc.). These aspects are organized into three areas: 1. Library collections. 2. Databases and specialized collection catalogues. 3. Specialist scientific journals and the like. For each area, we determine the characteristics defining the object of study, establishing a list of examples to which research could be applied, and the most appropriate bibliometric indicators to use in each case. By way of illustration, for example, in the case of a library collection, useful indicators could be: the distribution of items by year of publication, by author, by printer, by subject, and by language. In the case of journal articles, one would apply: Price's law to observe the growth in the number of articles and authors, Lotka's law to study the ratio between the numbers of articles and authors, or the productivity index to identify the principal producers, etc. And in the case of a database, one could analyze the information retrieved through the printers field to define the most productive circles in a given time period.

\section{Introducción}

Este trabajo se centra en la aplicación de la Bibliometría al estudio del fondo antiguo. Para ello en primer lugar hemos partido de la comprobación de la existencia o no de trabajos de investigación que se basen en este planteamiento metodológico, con el propósito de recopilarlos y conocer la metodología y características que los definen.

En segundo lugar, esbozamos unas vías de investigación que pueden orientar la aplicación de la Bibliometría al estudio de las colecciones de fondo antiguo conservadas en España. Estas vías la concretamos en torno a tres ejes o ámbitos:

1. Colecciones de bibliotecas.

2. Bases de datos y catálogos colectivos especializados.

3. Revistas científicas especializadas y afines.

El trabajo se fundamenta en la experiencia previa de los autores, tanto docente como investigadora en las disciplinas del fondo antiguo y de la Bibliometría.

Con la expresión fondo antiguo se suele aludir a la colección de una biblioteca. Esta colección suele estar formada por manuscritos, incunables e impresos fechados hasta el año 1800 inclusive $^{1}$. Así pues, el fondo antiguo de una biblioteca española está constituido fundamentalmente:

"por manuscritos e impresos de los siglos XV al XVIII. Las obras que constituyen ese fondo se conservan separadas del fondo moderno, y requieren de unos cuidados $y$ unas medidas de protección especiales, derivadas de su fragilidad y el escaso número de ejemplares existentes" (Marsá, 1999).

\section{Estado de la cuestión}

Los trabajos de investigación localizados que aplique la expresión Bibliometría al estudio del fondo antiguo son los siguientes: uno elaborado por los mismos autores que presentamos esta comunicación (Pulgarín, Herrera, Marroquín, 2007), otro de Herrero

\footnotetext{
${ }^{1}$ Para algunos autores se deberían ampliar esta fecha en un par de décadas.
} 
(1997), otro de Aguirre (1987) y varios relacionados con el estudio de publicaciones antiguas de Medicina: Guillén, et al. (1988), Puche (1975), Olagüe (1976), Sillero (1992); y de Farmacia: (Mansilla, 1984), Sánchez (1978).

Nuestro trabajo de 2007 pretende estudiar y difundir, de forma global, el fondo antiguo de la Biblioteca de la Real Sociedad Económica Extremeńa de Amigos del País (R.S.E.E.A.P). Para ello, se lleva a cabo la recopilación de los datos bibliográficos del fondo correspondientes a los siglos XVI-XVIII, datos que son organizados para su posterior tratamiento y análisis biblométrico y que se cotejan con el Catálogo Colectivo del Patrimonio Bibliográfico Español para observar la mayor o menor singularidad o rareza del fondo (los datos de la Biblioteca de la R.S.E.E.A.P. no están recogidos en el C.C.P.B.E.).

El trabajo de Herrero (1997) recoge en el título la expresión "análisis documental y bibliográfico" y el trabajo se centra en el diseño y elaboración de una base de datos para la descripción de una colección de libros antiguos del siglo XVI, el aspecto bibliométrico se reduce a la elaboración -a modo de resultados- de unos gráficos con los datos cuantitativos de las obras analizadas, según lugares de impresión, fecha de publicación, procedencia de los autores, lengua de publicación, tipos de escritura, encuadernaciones y materias. Algo parecido sucede con el de Aguire (1987) centrado en la literatura española de los siglos de oro, y que se plasma en el propio título al acompañar a la expresión Bibliometría con el adjetivo "elemental".

Respecto a las investigaciones de Medicina y Farmacia la mayoría están vinculadas a la Universidad de Valencia, pionera en España en los estudios bibliométricos, a partir de los trabajos del profesor Sánchez Piñero.

Otro grupo de trabajos que guardan cierta relación son los que se basan totalmente o en parte en el estudio de una determinada producción bibliográfica y/o editorial, y que suelen incorporar en su metodología algún tipo de análisis estadístico, por ejemplo el trabajo de Sáez y Marset (1993); pero la mayoría de este tipo de trabajos son más bien de carácter histórico y/o bibliográfico (Berger, 1988; Gil, 2004; Fernández, 1984; García, 2005; Liñán, 1992; Pardo, 1997; Suárez, 2005; Delgado y Cordón, 1990). Dentro de un planteamiento muy semejante tenemos que citar el grupo de trabajos de investigación denominados tipobibliografías, consisten en el estudio de la historia de la imprenta en una determinada ciudad, la base de la investigación es la localización de todos los impresos salidos de los talleres que se suelen adjuntar como un repertorio bibliográfico ${ }^{2}$.

A parte de estos estudios sólo tenemos constancia de algunas investigaciones sobre fondos antiguos de bibliotecas. Suelen ser de carácter histórico. Por ejemplo, sobre bibliotecas ya desaparecidas a partir de documentos conservados. Es el caso del trabajo de Vivas (2000), que analiza la biblioteca del convento de los dominicos de San Esteban de Salamanca a través de un manuscrito. En otros, los autores se limitan a reconstruir el índice o inventario de los libros, con más o menos detalle (Galende, 2000; Varela, 1999) - en algún caso se aprovecha para analizar los gustos sobre lecturas (San Martín, 1996).

\footnotetext{
${ }^{2}$ Gran parte de estas tipobibliografías son Tesis doctorales y ha sido publicadas por la editorial Arco / Libros
} 


\section{Desarrollo y resultados}

\section{Colecciones de bibliotecas}

Establecemos estas dos distinciones:

La primera, referente al tamaño de la colección, diferenciando entre grandes colecciones y pequeñas o medianas colecciones.

La segunda se basa en la existencia o no de un catálogo o base de datos con la descripción individual de los fondos.

En el caso de la primera distinción, para una colección que no sea excesivamente grande, se puede diseñar un estudio bibliométrico para describirla a grandes de rasgos y de manera global, por ejemplo que describa la distribución de los fondos por años de edición, por autores, por impresores, distribución temática y distribución por idioma. Como ejemplo de este planteamiento mencionamos el trabajo realizado sobre Biblioteca de la Real Sociedad Económica Extremeña de Amigos del País (Pulgarín, Herrera, Marroquín, 2007).

Si la colección es muy voluminosa sería conveniente un acotación previa del objeto de estudio que puede ser en función de las tipologías documentales o colecciones que integran el fondo (por ejemplo limitarnos al estudio de los incunables o los impresos del siglo XVI, etc.) o de otros aspectos como una materia determinada, un lugar de impresión, etc. También la acotación se pude establecer combinando varios asuntos (por ejemplo estudiar los impresos del XVI publicados en Lyon).

En el caso de la segunda distinción, si existe un catálogo o base de datos de acceso público el tipo de investigación coincide con el tercer ámbito de estudio que proponemos y que veremos a continuación. Si el catálogo o base de datos es de uso interno de la biblioteca tendremos que establecer una relación previa con los responsables para fijar que tipo de información nos puede facilitar, por ejemplo archivos con la distribución de las obras por los distintos campos de la base de datos (impresores, títulos, etc) y en función de ello ver qué datos podríamos cuantificar. Si no hay ningún tipo de herramienta informática de este tipo el trabajo se complica, pues, habría que realizar previamente este trabajo, que abarcaría -como muy bien describe Herrero (1996)- desde la elaboración del modelo de descripción bibliográfica hasta el diseño de base de datos que se va a utilizar para la confección del catálogo.

Para conocer las principales bibliotecas que cuentan con colecciones de libros antiguos en España recomendamos la obra de Rodríguez y Llordén (1998); y para localizar las bibliotecas que cuentan con catálogos y/o base de datos accesibles desde Internet los trabajos de Herrera (2003a y 2003b).

\section{Bases de datos y catálogos colectivos especializados}

Dentro de este grupo de recursos el que requiere un tratamiento especial, por su importancia y posibilidades como fuente para diseñar trabajos de investigación, es el Catálogo Colectivo del Patrimonio Bibliográfico Español (CCPB). Para justificar lo que acabamos de afirmar, describimos brevemente sus cualidades. 
El CCPB contiene la descripción y localización de libros y otros fondos bibliográficos, depositados en bibliotecas e instituciones espańolas públicas o privadas, que por su antigüedad, singularidad o riqueza forman parte del Patrimonio Histórico Español. Responde a un programa conjunto del Ministerio de Cultura y las Comunidades Autónomas, de acuerdo con la Ley 16/1985 de Patrimonio Histórico. Tiene la gran ventaja de ser un catálogo colectivo y por tanto una herramienta de gran utilidad, ya que da información sobre la existencia de una misma obra en un conjunto de bibliotecas (Velasco y Merlo, 2000).

Es un proyecto en fase de desarrollo y está en proceso continuo de ampliación y depuración.

- Monografías XV-XX (XX selectiva).

- Manuscritos y otro tipo de materiales (escasos, se incrementarán cuando finalice la catalogación de las bibliotecas españolas).

En la actualidad la mayor parte de los registros describen distintas ediciones de obras impresas entre los siglos XV y XX (hasta 1958), así como los ejemplares concretos de dichas ediciones existentes en las bibliotecas espańolas. Se han empezado a incluir también otros materiales bibliográficos (manuscritos, música impresa...).

Según los datos de la última actualización (24 de mayo de 2009). El contenido referente a las obras impresas (siglos $\mathrm{XV}-\mathrm{XX}$ ) es el siguiente:

- Registros bibliográficos: 887.550 .

- Registros de ejemplar: 2.487.738.

- Bibliotecas incluidas: 761.

Desde 1997 accesible en Internet <http://www.mcu.es/bibliotecas/MC/CCPB/ index.html>

La información que nos ofrece es importante y variada, se refiere tanto a las ediciones, como a los ejemplares concretos.

Información sobre las ediciones:

- Autor o autores y otros responsables (impresor, etc.).

- Título (se mantiene como aparece en la portada).

- Datos de edición.

- Datos de publicación (país/localidad, editor, impresor y fecha).

- Lengua del texto.

- Descripción física (hojas o página, ilustraciones, formato).

- Series editoriales.

- Notas, incluidas las signaturas tipográficas.

- Materias.

Información sobre los ejemplares:

- Comunidad autónoma (orden alfabético).

- Localidad. 
- Biblioteca.

- Signatura topográfica.

- Datos característicos.

- Estado de conservación.

- Encuadernación.

- Procedencia.

- Exlibris.

- Etc.

Los campos de la pantalla de búsqueda en la base de datos se corresponden en parte con la información sobre las ediciones, son los siguientes:

- Nombre de persona o entidad (autor).

- Título.

- Lugar de publicación.

- Impresor o editor.

- Fecha de impresión.

- Materia.

- Lengua.

Una vez fijadas las principales cualidades del CCPB la potencialidad de realizar estudios bibliométricos es evidente. Cada uno de los elementos del anterior listado, que permiten recuperar registros e información referentes esos elementos de las ediciones, puede ser objeto de un estudio bibliométrico, sólos o en combinación; y bien aplicado al conjunto de la base de datos, o estableciendo una acotación previa.

Por ejemplo, si nos fijamos en el lugar de publicación podemos elegir uno o varios lugares y precisar el volumen de obras publicadas en esos lugares que contienen el Catálogo. También se puede calcular ese volumen en relación a otras variables como una materia, una fecha determinada, etc.

Ahora nos detenemos en dos elementos, muy característico de los impresos antiguos en relación a los modernos. Nos referimos al impresor y al costeador.

El impresor es frecuente hasta el siglo XIX, cuando empieza a prevalecer el editor o editorial. Suele aparece redactado con el nombre de pila y primer apellido (a veces gentilicio). Suele ir introducido por expresiones propias, las más habituales (Reyes, 2003):

- "Por la viuda de..."

- "Por los herederos de..."

- "Por..."

- "En casa de..."

Expresiones en latín:

- "Apud..."

- "Excudebat..."

- "Ex typographia..."

- "In aedibus" 
Destacamos la costumbre de que se hicieran cargo de los talleres de impresión tras el fallecimiento de su creador la viuda, los hijos, regentes, operarios, etc. Y suele reflejarse en el nombre (Martín, 1998).

Respecto al costeador es la persona que financia la edición, es decir toma la iniciativa y se hace con el control del libro, mediante la adquisición del privilegio (requisito legal de la época para poder imprimir un libro), decide la imprenta que va a realizar el trabajo (si no es el mismo impresor), decide las características materiales del libro (firma un contrato con el impresor), paga todos los costes, asume los beneficios o las pérdidas. Su nombre aparece en la parte inferior de las portadas, al lado o debajo del lugar y del impresor. El nombre precedido de la fórmula:

- "A costa de..."

- "Véndese en casa de... mercader de libros"

- "A expensas de..."

- "Sumptibus..."

A veces puede ocurrir que el costeador se trata del mismo impresor, entonces a continuación del nombre del impresor aparece la expresión:

- "Y a su costa"

- "Y a sus expensas"

- "Vendese en su casa"

De todos modos el nombre del costeador no es demasiado frecuente en los impresos españoles, pues no existía la obligación de incluirlo.

Como propuesta de estudios bibliométricos centrados en el análisis de la información relativa a los impresores y costeadores, nos podemos basar en:

- Definir los círculos más productivos de un impresor o taller en un periodo cronológico concreto.

- Estudiar la evolución de un taller que ha pasado por varias etapas, fruto de los cambios de propiedad, reflejados en las modificaciones del nombre del taller: de tal modo que se puede calcular el volumen de la producción bibliográfica en cada etapa, contabilizando las obras impresas bajos los distintos nombres del taller.

- Calcular los libros que cuentan con costeador en relación con un periodo cronológico concreto, y/o con un lugar, y/o con un taller de impresión.

Otro aspecto del CCPB susceptible de investigar con las técnicas métricas es la información que el CCPB da sobre los ejemplares que se conservan, en las diferentes bibliotecas, referentes a una determinada edición. Así, podemos elegir un libro concreto que hemos localizado en el Catálogo y luego conocer cuantos ejemplares indica que existen del mismo y en qué bibliotecas. Con esta información podemos establecer un indicador de la "rareza" de la obra en cuestión, partiendo de la premisa de que la existencia de un menor número de ejemplares acentúa su valor, a ser un bien escaso. 
Finalmente queremos destacar que se puede emplear como una importante herramienta de comparación, nos referimos al caso de que estemos estudiando un fondo que todavía no ha sido recogido en el CCPB, podemos comprobar, mediante búsquedas en este Catálogo, qué obras de las conservadas en la biblioteca que estamos estudiando están presentes y cúales no. Es una forma de señalar la mayor o menor singularidad de los fondos analizados, partiendo de la premisa de que un libro que no esté recogido en el catálogo -o del que indique que existen pocos ejemplares- lo consideramos que tiene cierta "rareza" o "singularidad" por su escasez, pues, no podemos olvidar que hoy en día el CCPB es el principal y más eficaz instrumento de control del patrimonio bibliográfico español. Esta posibilidad metodológica la hemos empleado en el trabajo, ya mencionado, de la Biblioteca de la Real Sociedad Económica Extremeña de Amigos del País (Pulgarín, Herrera, Marroquín, 2007).

En segundo lugar de importancia tenemos que considerar los catálogos y bases de datos de las bibliotecas universitarias. De estas bibliotecas las que cuentan con colecciones de fondo antiguo, progresivamente, han ido diseńando recursos para facilitar el acceso y difusión de estos fondos, entre los que se encuentran los catálogos.

Distinguimos tres modelos de catálogos:

- Los catálogos generales, comunes para el fondo antiguo y moderno.

- Los catálogos generales, que cuentan con un subcatálogo para el fondo antiguo.

- Los catálogos específicos e independientes para el fondo antiguo.

Los dos últimos son los que están mejor adaptados a las características de los libros antiguos. Desde el punto de vista técnico el modelo más extendido está formado por una interfaz que permite a los usuarios acceder al sistema e interactuar con él a través de un visor web. Presenta las características principales de los web-opac actuales: interfaz gráfica de usuario de aspecto web, amigabilidad, utilización de las herramientas propias del web, incorporación de hiperenlaces, etc., que se concretan en los siguientes componentes formales: 1. Página de consulta: formada por los formularios destinados a la recuperación de la información. Incluye dos tipos de página de consulta, una simple con pocas opciones y otra avanzada en la que se pueden combinar diversos términos. 2. Página de resultados: lista que contiene la información básica de los documentos que se ajustan a la pregunta formulada, da una visión global para facilitar la valoración del interés del documento a partir de su descripción resumida. La información se presenta dentro de una tabla. 3. Visualización de los registros: el registro se muestra con la información de todos los campos, algunos actúan de hiperenlaces para navegar por el catálogo, son los campos autor, signatura, citado en, procedencia, materia y lugar de impresión. La visualización del registro se completa con las funciones: pasar al registro anterior o posterior, comenzar de nuevo, exportar, cambiar de formato de visualización, regresar al listado, limitar la búsqueda, etc.

Un ejemplo temprano de este tipo de catálogo es el catálogo del fondo antiguo de la Universidad de Granada ${ }^{3}$ que cuentea con esta peculiaridad: muchos de los registros incluyen un campo que permite visualizar las imágenes digitalizadas de algunas de las

\footnotetext{
3 U.R.L: <http://www.ugr.es/\%7Ebiblio/>
} 
páginas más relevantes del libro. Esta tendencia de incluir el texto digitalizado (completo o una selección de páginas) está siendo incorporada por más bibliotecas universitarias (Cádiz, Castilla-La Mancha, Complutense, Zaragoza o Salamanca).

Respecto a las posibilidades de estudios bibliométricos que estos catálogos presentan, son muy semejantes a las comentadas para el CCPB, añadiendo para los catálogos que cuentan con textos digitalizados la posibilidad de incorporar este dato (por ejemplo, en el caso del Catálogo de Granada, se puede precisar el porcentaje de registros que incluyen imágenes digitalizadas y cuántas).

Un caso especial es el de la Universidad de Salamanca, pues, recientemente ha presentado el "Proyecto Exlibris", centrado en enriquecer la información de su catálogo de fondo antiguo con datos relativos a la historia del ejemplar que permita conocer su particular historia: las sucesivas signaturas, reflejo de su ubicación en diferentes bibliotecas o de los cambios en la ordenación en una sola; las marcas de posesión y uso; la presencia de notas de lectura; los testimonios de haber sido libro sospechoso o condenado; la encuadernación, como marca de posesión y reflejo de las épocas artísticas ${ }^{4}$. Las entradas que componen el listado de posesores y procedencias de los libros tiene la siguiente estructura:

- Nombre: es la forma autorizada que se ha dado a la persona o institución. Bajo esa forma habrá de ser buscado en el catálogo online. Por ejemplo: Quevedo, Francisco de

- Fechas: permite situar cronológicamente a la persona o institución. En aquellos casos en que el usuario no ha sido del todo identificado, esta aproximación se ha hecho a partir del examen de la letra y el término post quem que supone la fecha del libro.

- Información biográfica: cuando se ha podido identificar al usuario, se ofrecen aquí algunos datos sobre su profesión, actividades y cargos, actividad literaria, etc. En ocasiones, esta información propone un posible usuario, cuando la identificación no es segura a partir de sus marcas de posesión.

- Biblioteca: cuando se tiene alguna información sobre la formación y destino de la biblioteca de la institución o propietario, se dan unas breves indicaciones.

- Motto: se transcribe el lema o frase que a veces acompaña al exlibris o al escudo heráldico.

- Exlibris: se transcribe la mención o menciones con las que suele identificarse el posesor. Se ha escogido aquella que resulta más significativa para la identificación, aunque existen casos en que son transcritas varias formas si las variaciones son significativas. La transcripción va acompañada de una o varias imágenes. También se han tomado imágenes de las anotaciones encontradas en el libro cuando la atribución al usuario cuyo nombre aparece en él es bastante probable.

- Bibliografía: sin pretender ser exhaustivos, se recoge algún ítem bibliográfico donde pueden hallarse datos sobre el usuario y/o su biblioteca, que en ocasiones han resultado decisivos para la identificación.

\footnotetext{
${ }^{4}$ Para más información véase Proyecto Exlibris <http://campus.usal.es/ -bgh/800/html/indexlib.htm> [Consulta 4 junio 2009].
} 


\section{Revistas científicas especializadas y afines.}

El tercer ámbito de estudio propuesto son las revistas, con el propósito de localizar -y posteriormente diseñar estudios de tipo bibliométrico- los artículos sobre fondo antiguo. Establecemos cuatro grupos de revistas. En la selección, hemos tenido en cuanta como criterios de selección, además de que sean revistas que recojan o admitan trabajos de fondo antiguo, que sea revistas consolidadas y que estén activas.

Un primer grupo de revistas con las que se puede trabajar son las de Biblioteconomía y Documentación. De éstas seleccionamos las que nos consta que dan cabida a trabajos de esta materia son:

- Boletín de la ANABAD.

- Revista General de Información y Documentación.

- Boletín de la Asociación Andaluza de Bibliotecarios.

- Aabadom: Boletín de la Asociación Asturiana de Bibliotecarios, Archiveros,

Documentalistas y Museólogos.

- Documentación de las Ciencias de la Información.

- Ibersid: revista de sistemas de información y documentación.

- Anales de Documentación.

- Scire: Representación y Organización del conocimiento.

Otro grupo de revistas son las relacionadas con instituciones de ámbito provincial normalmente vinculadas a las diputaciones provinciales, academias, fundaciones, etc. que recogen trabajos de investigación de ámbito local de todas las disciplinas, con una especial atención a las humanidades en general. Los estudios relacionados con las colecciones de fondo antiguo, que con bastante frecuencia se centran en el estudio de colecciones locales, particulares, etc, vinculadas a un determinado ámbito geográfico, encuentran en estas revistas su principal vía de publicación, pues, responden perfectamente al tipo de trabajos que suelen publicar. Revistas que responden a estas características tenemos en nuestro país las siguientes:

- Revista de Estudios Extremeños.

- Anales toledanos.

- Boletín del Instituto de Estudios Giennenses.

- Cuadernos de estudios gallegos.

- Boletín de la Real Academia de Córdoba de Ciencias, Bellas Letras y Nobles Artes.

- Boletín de la Real Sociedad Vascongada de Amigos del País.

- Príncipe de Viana.

- Anales del Instituto de Estudios Madrileños.

- Al-Basit: Revista de estudios albacetenses.

- Alcántara: revista del Seminario de Estudios Cacereños.

- Anals de la Real Acadèmia de Cultura Valenciana (Anales de la Real Academia de Cultura Valenciana).

- Andalucía en la historia.

- Anuario del Instituto de Estudios Zamoranos Florián de Ocampo. 
- Archivo hispalense: Revista histórica, literaria y artística (Diputación de Sevilla).

- Ars et sapientia: Revista de la asociación de amigos de la Real Academia de Extremadura de las letras y las artes.

- Ateneo: revista cultural del Ateneo de Cádiz.

- Berceo (Instituto de Estudios Riojanos).

- Biblioteca: estudio e investigación (Ayuntamiento de Aranda de Duero).

- Boletín auriense.

- Boletín de la Institución Fernán González.

- Boletín de la Real Sociedad Económica de Amigos del País de Tenerife.

- Boletín de la Sociedad Castellonense de Cultura.

- Boletín del Real Instituto de Estudios Asturianos.

- Brigecio: revista de estudios de Benavente y sus tierras.

- Cuadernos abulenses (Diputación de Ávila).

- Cuadernos de Aragón (Institución Fernando el Católico).

- Cuadernos de estudios manchegos (Instituto de estudios Manchegos).

- Estudios canarios: Anuario del Instituto de Estudios Canarios.

- Toletum: boletín de la Real Academia de Bellas Artes y Ciencias Históricas de Toledo.

- Estudios segovianos (Centro de estudios segovianos).

- Estudis balearics (Institut d'Estudis Baleárics).

- Estudis castellonencs (Diputación de Castellón).

- Wad-al-Hayara: Revista de estudios de Guadalajara.

- Studia Zamorensia (UNED Zamora, Centro de la Universidad Nacional de

Educación a Distancia de Zamora).

- Tierras de León: Revista de la Diputación Provincial.

- Sancho el sabio: Revista de cultura e investigación vasca.

- Salamanca: revista de estudios (Diputación de Salamanca).

- Rolde: Revista de cultura aragonesa.

- Revista de Girona (Diputación de Girona).

- Revista de humanidades y ciencias sociales (Instituto de Estudios Almerienses).

- Publicaciones de la Institución Tello Téllez de Meneses (Palencia).

- Anales Complutenses (Institución de Estudios Complutenses).

- Revista de historia Jerónimo Zurita (Institución Fernando el Católico).

El tercer grupo lo forman las revistas especializadas en patrimonio bibliográfico y bibliofilia. Por lo tanto, son las revistas donde los artículos de nuestro interés estarán mejor representados. Son pocas las revistas de estas características:

- Pliegos de Bibliofilia (acaba en 2004).

- Hibris: Revista de bibliofilia.

- Cuadernos del siglo XVIII.

- Cultura escrita y sociedad.

- Pecia Cumpletense.

- Signo. Revista de historia de la cultura escrita.

- Syntagma: Revista del Instituto de Historia del Libro y de la Lectura.

- Cartas Diferentes: revista canaria de patrimonio documental. 
- Noticias bibliográficas: Revista bibliográfica anticuaria internacional (desde 1998 hasta 2006).

- Boletín de la Biblioteca de Menéndez Pelayo.

- Boletín de la Real Academia Española.

El último grupo que hemos definido lo forman las revistas de humanidades en general, que por su temática generalista, y ante la escasez de revistas sobre bibliofilia (como hemos visto en el grupo anterior), son apropiados para recogen trabajos de libros antiguos. Con frecuencia las publican Departamentos o Facultades de humanidades:

- Ámbitos: revista de estudios de ciencias sociales y humanidades.

- Bienes culturales: revista del Instituto del Patrimonio Histórico Español.

- Boletín Millares Carlo.

- Humanitas: revista de la Facultad de Humanidades y Ciencias de la Educación de la Universidad de Jaén.

- Studium: Revista de humanidades (Universidad de Zaragoza: Facultad de Humanidades y Ciencias Sociales de Teruel).

- Revista de estudios andaluces (Universidad de Sevilla).

- Revista de investigación universitaria (Universidad Nacional a Distancia).

- Patrimonio cultural: Documentación, estudios, información (Conferencia Episcopal Española: Comisión Episcopal para el Patrimonio Cultural).

- Oppidum: cuadernos de investigación (IE Universidad).

- Magister: Revista miscelánea de investigación (Universidad de Oviedo).

- Ínsula: revista de letras y ciencias humanas.

Respecto a los indicadores más propios para aplicar en el estudio biblométrico de los artículos pueden ser: la ley de Price para ver el crecimiento del número de artículos y autores, la ley de Lotka para la relación de proporcionalidad entre el número de artículos y autores, o el índice de productividad para la identificación de los principales productores, etc.; También nos parece interesante precisar la cobertura temática de los estudios, por ejemplo: si se refieren a colecciones completas de bibliotecas, a una tipología documental determinada (incunables, manuscritos, impresos), a aspectos particulares de los componentes de los libros (ilustraciones, encuadernaciones, etc.); determinar el enfoque metodológico de los estudios (elaboración de repertorios, elaboración de catálogos, estudios filológico-literarios, estudios desde la perspectiva de la bibliografía material, etc.); o trazar el perfil de los autores: profesores universitarios, bibliófilos, bibliotecarios, etc.

Otro aspecto interesante es comprobar si los artículos relacionados con el fondo antiguo publicados en los diferentes grupos de revistas establecidos tienen algunas características diferenciadoras, según pertenezcan a uno u otro.

\section{Referencias bibliográficas}

Aguirre, J.L. (1987). Bibliometría elemental sobre literatura española de los siglos de oro. Boletín de la Sociedad Castellonense de Cultura, 63 (3), 331-341. 
BERGER, Ph. (1988). La evolución de la producción editorial española entre 1501 y 1520. En Cátedra García, P.M.; López-Vidriero Abello, M.L. (coord.). El libro antiguo español: actas del Primer Coloquio Internacional, (Madrid, 18 al 20 de Diciembre de 1986) (pp. 63-72). Salamanca: Ediciones Universidad de Salamanca.

Delgado López-Cozar, E.; Cordón García, J.A. (1990). El libro: creación, producción y consumo en la Granada del siglo XIX. Granada: Universidad de Granada.

Domínguez Guzmán, A. (1992). La imprenta en Sevilla en el siglo XVII: (catálogo y análisis de su producción), 1601-1650. Sevilla: Secretariado de Publicaciones de la Universidad.

Fernández Dueñas, A. et al. (1984). La producción médico editorial cordobesa en el Barroco: análisis, revisión y comentarios. Boletín de la Real Academia de Córdoba de Ciencias, Bellas Letras y Nobles Artes, 55 (106), 347-357.

Galende Díaz, J.C. (2000). La biblioteca del colegio mayor salmantino de San Bartolomé en el siglo XVIII. Revista General de Información y Documentación, 10 (2), 33-69.

García Cuadrado, A. (2005). Una imprenta murciana del siglo XVIII: aproximación a su producción bibliográfica (1759-1780). En Escavy Zamora, R. (coord.) Amica Verba: in honorem Prof. Antonio Roldán Pérez (vol. 1, pp. 299-316). Murcia: Universidad de Murcia, Servicio de publicaciones.

Gil Fernández, L. (2004). La producción editorial de signo humanístico en la época de los Reyes Católicos. Silva. Estudios de Humanismo y Tradición Clásica, 3, 203-222.

Guillén Grima, F. et al. (1998). Análisis bibliométrico comparativo de la producción sobre Salud pública con el resto de la producción científica médica en el siglo XVIII. En Valera, M.; Egea, M.A. y Blázquez, M.D. (eds.). VIII Congreso Nacional de Historia de la Medicina. Libro de actas (vol. 3, pp. 1197-1213). Murcia: Departamento de Historia de la Medicina.

Herrera Morillas, J.L. (2003). El patrimonio bibliográfico español a través de los catálogos virtuales. En III Jornadas Andaluzas de Documentación: Organizaciones electrónicas: situación actual y perspectivas de la e-documentación: comunicaciones, experiencias profesionales, póster y presentaciones técnicas (pp. 41-250). Sevilla: Asociación Andaluza de Documentalistas.

. (2003). Recursos digitales para el acceso y difusión del libro antiguo. Capítulo 5 de Tratamiento y difusión digital del libro antiguo: directrices metodológicas y guía de recursos (pp. 261 319). Gijón: Trea.

Herrero Pascual, C. (1997). Análisis documental y bibliométrico de los libros del siglo XVI de la Biblioteca de los Obispos (Murcia). Revista General de Información y Documentación, 7 (2), 141-166.

Liñán Maza, M. del C. (1992). La producción bibliográfica andaluza del siglo XIX en la Biblioteca de la Facultad de Veterinaria de Córdoba. En Hernández Rodríguez, S (ed.). In memoriam al profesor doctor D. Francisco de Paula Martínez Gómez (pp. 951-968). Córdoba: Universidad de Córdoba, Servicio de publicaciones.

Mansilla Legorburu M.E. (1984). Catalogación, estudio estadístico y bibliométrico de los libros de interés histórico-farmacéutico que se encuentran en la biblioteca central de la Universidad literaria de valencia (Tesis doctoral, Universidad de Valencia).

Marsá Vila, M. (1999). El fondo antiguo en la biblioteca. Gijón: Trea.

Martin Abad, J. (1998). Incunables e impresos antiguos. En Díez Carrera, C. (dir.). Los materiales especiales en las bibliotecas (pp. 63-12). Gijón: Trea.

Olagüe de Ros, G. (1976). La literatura médica sobre epilepsia: Siglos XVI-XIX: Análisis bibliométrico. Valencia: Cátedra e Instituto de Historia de la Medicina. 
Pardo Tomás, J. (1997). La producción impresa de libros científicos en la Corona de Aragón durante el siglo XVI. En Serrano Martí, E.; Sarasa Sánchez, E. (coord.). La Corona de Aragón y el Mediterráneo: siglos XV-XVI (pp. 231-268). Zaragoza: Institución Fernando el Católico.

Puche Azarín, P. (1975). La literatura médica española del siglo XVIII. Inventario, análisis bibliométrico y estudio semántico. Valencia: Cátedra de Historia de la Medicina (Tesis de Licenciatura).

Pulgarín Guerrero, A.; Herrera Morillas, J.L; Marroquín Martínez, L. (2007). Estudio bibliométrico de la Biblioteca de la Real Sociedad Económica Extremeña de Amigos del País. Parte I, colección de los siglos XVI-XVIII. Revista general de información y documentación, 17 (2), 186-208.

Reyes Gómez, F. de los (2003). Estructura formal del libro antiguo. En Pedraza Gracia, M.J.; Clemente San Román, Y.; Reyes Gómez, F. de los. El libro antiguo (pp. 207-247). Madrid: Síntesis.

Sáez Gómez, J.M; Marset Campos, P. (1993). La producción científico-médica murciana en el siglo XVIII. Llull. Boletín de la Sociedad Española de Historia de las Ciencias, 16 (31) 537-548.

Sánchez Serena, M.A. (1978). La literatura farmacéutica española, 1494-1800. Inventario, análisis bibliometrico y estudio semántico (Tesis Doctoral, Universidad de Valencia).

Sillero Sarasua, M.P. (1992). La biblioteca de Philipp Hauser. Análisis bibliométrico e inventario (Tesis doctoral, Universidad de Sevilla).

Suárez de la Torre, L. (2005). La producción de libros, revistas, periódicos y folletos en el siglo XIX. En Clark de Lara, B.; Speckman Guerra, E. (coords.). La república de las letras: asomos a la cultura escrita del México decimonónico (vol. 2, pp. 9-28). México: Universidad Nacional Autónoma de México.

Varela Orol, C. (1999). Las "bibliotecas" de la biblioteca universitaria de Santiago en el siglo XVIII. En III Jornadas de Arquivos, Bibliotecas, Centros de Documentación e Museos de Galicia: As Novas Tecnoloxias o Servicio do Usuario (pp. 513-520). Santiago de Compostela: Xunta de Galicia.

Velasco de la Peña, E; Merlo Vega, J.A. (2000). Nuevas formas para el acceso al libro antiguo. Obtenida el 29 de junio de 2009, de http://exlibris.usal.es/merlo/escritos/pdf/aib.pdf

Vivas Moreno, A. (2000). La biblioteca del convento de los dominicos de San Esteban de Salamanca en el siglo XVIII. Revista General de Información y Documentación, 10 (2), 71 103. 